\title{
Design of the internal space of the commercial building
}

\author{
Wendi Tan ${ }^{1, a}$, Li Zhu ${ }^{1, b}$ \\ ${ }^{1}$ North China university of science and technology, Tangshan, Hebei, 063009, China \\ a710642897@qq.com, b8498350@qq.com
}

\begin{abstract}
Keywords: Commercial buildings ; The atrium space ; Channel space ; Commercial exhibition space
\end{abstract}

Abstract. This article researches on the design method of commercial building interior space, make research on atrium space, channel space and commercial exhibition space, combining the space design, aesthetic design, human feelings, and the commercial profit objective aspects. This article is different from previous studies which study the space only from the perspective of aesthetics or the feelings of people's point of view, and it has important value on the commercial real estate project planning and the design method of the commercial center.

\section{Introduction}

The most basic power operation of commercial buildings is profit, realize thecommodity exchange is the main function, in addition, the modern commercial buildings have also been a surplus of many other functions, such as communication, leisure, entertainment functions are continuously improved, the commercial buildings become the true sense of the city lounge, has also become an important window to show the city image. When the architect design, they should pay attention to the art space atmosphere, people in the interior space feeling, also more to try to think from the angle of space mode how to affect the business. This paper focuses on the research of three kinds of space of commercial space in the most characteristic, the first is the atrium space, the second is the channel space, third are commercial exhibition space.

\section{The design of the atrium space}

Atrium space is the most important hub space in commercial buildings, the design of the atrium space is very important. The atrium space with successful design can give a person with smooth, bright feeling, and also can stimulate the interest in visiting customers.

Spatial characteristics of the atrium. Commercial buildings in the atrium space is generally connected several floors in the vertical direction. Atrium space has a huge scale and very open. People in the atrium can see the space image of different floors at the same time. Therefore, the atrium space has the characteristics of obvious flow space. From the perspective of the atrium surrounding elements defined. The design method of ring shape corridor is common. This layout method can form an optimal liquidity space. At the same time, the defining elements are arranged generally glass ceiling transparent top, based on fusion of indoor space and outdoor space. Commercial buildings in the most common atrium forms include two kinds: Court atrium and a linear atrium. The inner court building atrium can be processed into an oval, round, square and other forms, from the surrounding hallways look to the atrium, the visual focus falls on the center of the atrium, features have static space; linear atrium showed characteristics of belt shaped space, visual focus change constantly with people moving in the atrium on both sides of the corridor, can transform in different floors. Therefore, the atrium space has more obvious dynamic space feeling.

Function of the atrium space. Atrium space function is first traffic organization. Large atrium space often occupies a central position, multiple channels set around the atrium space. The channel is connected to other functional areas and commercial building's atrium space, atrium 
space become an important transport hub; atrium space can also play the role of other features, fairs, business performances and other activities can be carried out within this space; at the same time, the seat arranged in the atrium space provides a temporary rest place for the customer; due to range through the atrium space can look at across the floor, but also to enhance the visibility of the surrounding shops located in the atrium, enhance the value of the shops, the atrium surrounding can also hanging advertising, plays the role of propaganda, increase the mall advertising revenue.

Communication facilities of the atrium space. Atrium space is connected with a plurality of space, is the best area to people for direction change. There are two kinds of vertical lifting equipment most commonly located in the atrium space: Elevator and escalator. Sightseeing elevator can make the person in it obtain dynamic feeling when the elevator is running. And the elevator itself is very beautiful, the elevator has become an important landscape element, but by the lift capacity constraints, the elevator can not serve as the main lifting equipment in commercial buildings. The escalators in the atrium space is more common, the escalator has the characteristics of large capacity and oriented, as a means of connection between floors, escalator increased value of shops located in the upper floor, is also the landscape elements.

\section{Design of channel space}

The channel is spatial strap shaped arrangement in the surrounding shops. Channel can be divided into three types: business hall type arrangement, pedestrian street layout mode and the pedestrian street with atrium arrangement.

Layout of business hall type. When the goods on the shelves to display, and between different brand only divided by region, only a very small amount of setting wall or is no wall between the various regions, people have a wide field of vision in the channel, the line of sight won't get blocked, people can see the large area of commercial space, see a lot of goods at the same time. The advantage of this arrangement is that between people and goods are quite closely related, can stimulate the people's shopping interest. This kind of aisle located in open space may have a width between 3 4 meters, too wide will cause the waste of space.

layout of Indoor pedestrian street. This arrangement is refers to the channel on both sides are surrounded by shops. Between the shops and shops completely separated, and for the channel side using large glass window or is completely open, close links between the shops and channel, people can obtain continuous shopping experience in channel. When people move in the channel, as shops arranged in both sides of the channel, the customer in addition to see shops goods can only look to the end of the channel(figure1). Therefore, the customer is very difficult to obtain the open space feeling. From the channel space size perspective, when the channel space narrow and long, the space is closed, people feel depressed, therefore, the main channel width should be controlled in the 8meters, secondary channel width should be controlled between $4 \sim 6$ meters.

layout of pedestrian street with atrium. We have already mentioned in the above discussion that the pedestrian street layout of interior space monotonous and closed. We can modify the space, to make it become a combination of pedestrian and the atrium arrangement. We can increase the width of the street space, atrium space formed between channels. Therefore, this method can form two parallel but independent shopping streets(figure2). At the side which lay out shop, so it is relatively closed; at the other side is atrium, so it is very open. Therefore, space feeling is very rich, spatial dynamic. Because of the space is open, and the flow distribution in the two pedestrian street, so the width of the channel can be properly reduced than walking street, between $4 \sim 5$ meters is appropriate.

\section{Design of commercial exhibition space}

Merchandise display space design includes three aspects: the first is the analysis of format, the second is the choice for shops location, and the third is the space division. 
Format analysis. Industry analysis is a necessary condition for the commercial project operation. Space design without format analysis, is not able to guarantee the profit. Commercial activities can be divided into retail, catering, cultural entertainment and living service. Department stores can be divided into clothing, food, daily general merchandise category and other elements; catering divided club, snacks, coffee bar form; cultural entertainment into theater, KTV, gym, bookstores, children's Park and other forms; life services include beauty salons, dry cleaning shops, banks and other forms of. Three kinds of commercial activities need to cooperate with each other, and maintain a certain proportion. And appropriately increase the proportion accounted for merchandise, even occupy the main position.

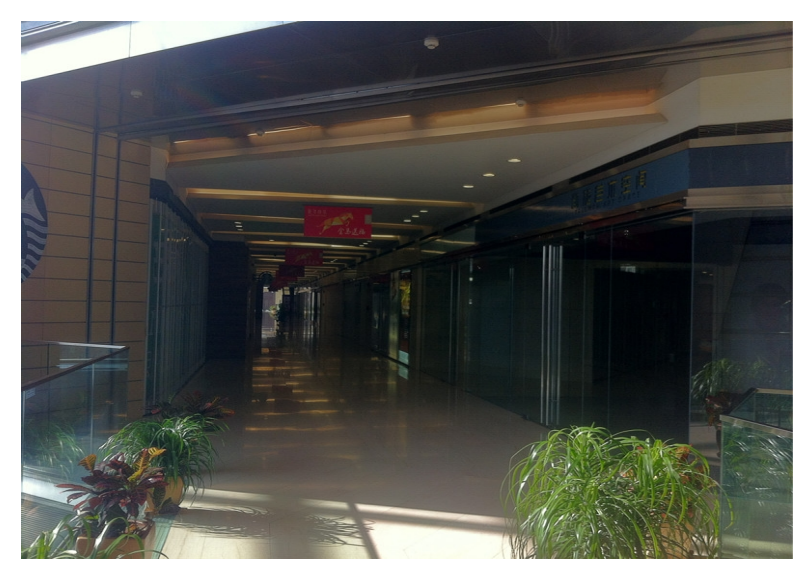

Fig.1 layout of Indoor pedestrian street

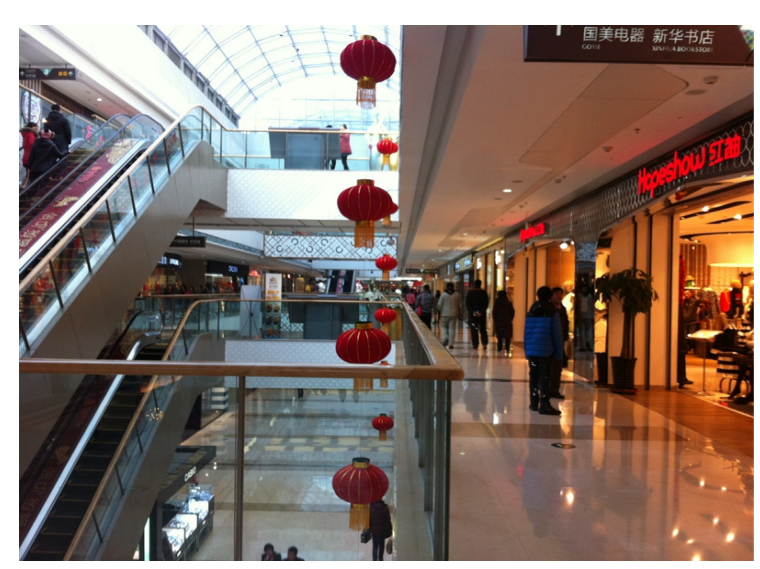

Fig.2 layout of pedestrian street with atrium

Shop location choice. After determining a commercial center which contains the commercial activities, we have to determine the location of various business activities. Considering from the vertical, department store type suitable for the configuration on the lower floor, and food, children's Park, theater and other projects can be configured in the floor is relatively high level, because the latter strong purpose, therefore, appropriate to reduce the accessibility will not affect traffic. At the same time, for some of the main shop, because they have a huge impact on the image of stores, so they must be set at the best position.

Division of commercial space. Set the parking lot in the commercial building basement approach more common. And separate commercial building mostly adopts the structural form of frame structure, in order to make the column grid formation can also facilitates dividing shops and divided spaces, spacing between 8.4 11 meters approach commonly used. The width and depth of the shops are important influencing aspects of shops space feeling, influence the value of the shops. Shops have relatively high value of width between $6 \sim 10$ meters, the depth of8 15 meters in between. Judging from the story, too short story leads to curb space, high storey will result in a waste of energy in lighting and air-conditioning equipment, thus removing the necessary equipment occupied space, the first floor clear height is in 4 meters of above, the floor clear height is in 3.6 meters of above is feasible.

\section{Conclusions}

Commercial building is different from other types of public buildings, commercial building design needs to ensure the commercial profit as the main purpose, in addition to meet the public needs of society, including aesthetic, recreational, entertainment etc.

\section{References}

[1] Jian Zeng. The planning and design of modern commercial buildings. Tianjin: Tianjin University press (in Chinese) 
[2] Yingjie Wu.Analysis of the atrium in commercial building design. Shanxi architecture, 201128 (in Chinese)

[3] Xiangyu Yuan.Study on commercial complex atrium space design. Master thesis, 2007 (in Chinese) 